\title{
Hipercorrección en los Programas de Noticias en la Televisión de la República Dominicana
}

Orlando Alba

Brigham Young University - Provo, orlando.primero.oa@gmail.com

Follow this and additional works at: https://scholarsarchive.byu.edu/facpub

Part of the Spanish and Portuguese Language and Literature Commons

\section{Original Publication Citation}

Hipercorrección en los Programas de Noticias en la Televisión de la República Dominicana.

\section{BYU ScholarsArchive Citation}

Alba, Orlando, "Hipercorrección en los Programas de Noticias en la Televisión de la República Dominicana" (2009). Faculty Publications. 1222.

https://scholarsarchive.byu.edu/facpub/1222

This Peer-Reviewed Article is brought to you for free and open access by BYU ScholarsArchive. It has been accepted for inclusion in Faculty Publications by an authorized administrator of BYU ScholarsArchive. For more information, please contact ellen_amatangelo@byu.edu. 


\title{
HIPERCORRECCIÓN EN LOS PROGRAMAS DE NOTICIAS EN LA TELEVISIÓN DE LA REPÚBLICA DOMINICANA
}

\author{
Orlando Alba (2009) \\ Brigham Young University
}

\section{INTRODUCCIÓN}

Un hecho muy conocido dentro de la comunidad académica internacional es que el español hablado por los dominicanos constituye uno de los dialectos hispánicos más radicales en cuanto a la variabilidad de algunas de sus consonantes. Esto se puede ilustrar, por ejemplo, con los procesos de cambio a que están sometidos los sonidos /r/ y /l/ tanto en posición final de sílaba interna de palabra como al final de palabra, y la nasal /n/ al final de palabra. En este sentido, en las diversas regiones del país se producen distintas realizaciones fonéticas, condicionadas casi siempre por el estilo de habla y por el nivel sociocultural de los hablantes: puerta: [puérta, puétta, puélta, puéita]; mujer: [muhér, muhé, muhél, muhéi]; último: [último, úrtimo, úitimo]; pan: [pay, pã] (Jiménez Sabater 1975; Haché de Yunén 1982; González 1990; Alba 1990, 2004).

Ahora bien, el fenómeno que mejor representa el radicalismo consonántico del español dominicano es, sin duda, el avanzado proceso de desgaste que experimenta la $/ \mathrm{s} /$ al fin de sílaba y de palabra. El tema ha sido objeto de estudio en reiteradas ocasiones y se menciona en los más diversos tratados de dialectología hispánica (Zamora y Guitart 1982, Lipski 1994, Moreno de Alba 2007). Algún investigador, basándose en los frecuentes casos de eliminación (lito, en vez de listo; tre, en lugar de tres) que se escuchan y en los ejemplos de ultracorrección que descubre (fisno, por fino) ha llegado al extremo de postular la hipótesis de la inexistencia de la /s/ a nivel subyacente en el sociolecto bajo del país (Terrell 1986). ${ }^{1}$ Se sabe que incluso en el habla del grupo social alto, son notables los índices de eliminación, si bien es cierto que la pronunciación aspirada, parecida a una jota ( $m i \underline{\mathbf{h}} m o$, en vez de mismo), encarna la variante que mejor identifica el habla de este sector socioeconómicamente privilegiado de la sociedad.

Frente a este estado de cosas, es particularmente chocante el comportamiento de los

\footnotetext{
${ }^{1}$ Con argumentos contundentes, Humberto López Morales (1990) rechaza la radical interpretación de Terrell. La utilización de nuevos datos le permite comprobar que el cambio de estilo conlleva una reducción importante de las eliminaciones, lo que, entre otras cosas, hace insostenible la hipótesis de la inexistencia de la /s/ a nivel subyacente. 1
} 
locutores y los periodistas que intervienen en los medios orales de comunicación en el país en lo concerniente a la pronunciación de la /s/ final de sílaba y de palabra. Una simple observación de los programas de noticias en la televisión dominicana permite descubrir cómo la forma plena [s], la sibilante, no solo se mantiene prácticamente en la totalidad de las ocasiones posibles, sino que también es objeto de una articulación exageradamente tensa. Se trata de un hecho tan perceptible que, con frecuencia, el escuchar tales emisiones provoca en muchos oyentes la sensación de desagrado que suele suscitar la falta de naturalidad y de autenticidad.

El objetivo principal de esta investigación consiste, precisamente, en intentar encontrar una explicación a ese fenómeno, es decir, al hecho de que los comunicadores (los presentadores o lectores de noticias y los reporteros), exhiben unos índices elevadísimos de retención del segmento [s], en fuerte contraste con la situación que caracteriza el habla culta del país.

El corpus en que se basa el estudio está compuesto por diez segmentos de diez minutos de duración cada uno, correspondientes a programas de noticias de cuatro de los canales de mayor audiencia de la televisión dominicana. Cada segmento contiene un promedio de 1,000 palabras. Se analizan todas las incidencias de la consonante /s/ situadas en posición final de sílaba y de palabra, con el fin de descubrir: A- cuándo el sonido es pronunciado plenamente, como [s] ([es $t o]) ; \mathbf{B}$ - en qué casos se manifiesta débilmente como un soplo aspirado [h] ([e $\underline{\mathbf{h}} t o])$; C- cuándo se suprime por completo [Ø] ([eto]). 


\section{RESULTADOS GENERALES}

El corpus analizado contiene un total de 2,656 casos de /s/ en posición final de sílaba, situados tanto en el interior (contras $t e$, es $\underline{\text { spranza }}$ ) como al fin de la palabra (más, niños $)$. Como se observa en la figura 1, el índice de eliminación del segmento /s/ se sitúa en el 10\%, en tanto su retención plena supera levemente el 63\%. Poco más de la cuarta parte del total se manifiesta por medio de una articulación relajada, aspirada, que se representa con el signo gráfico h.

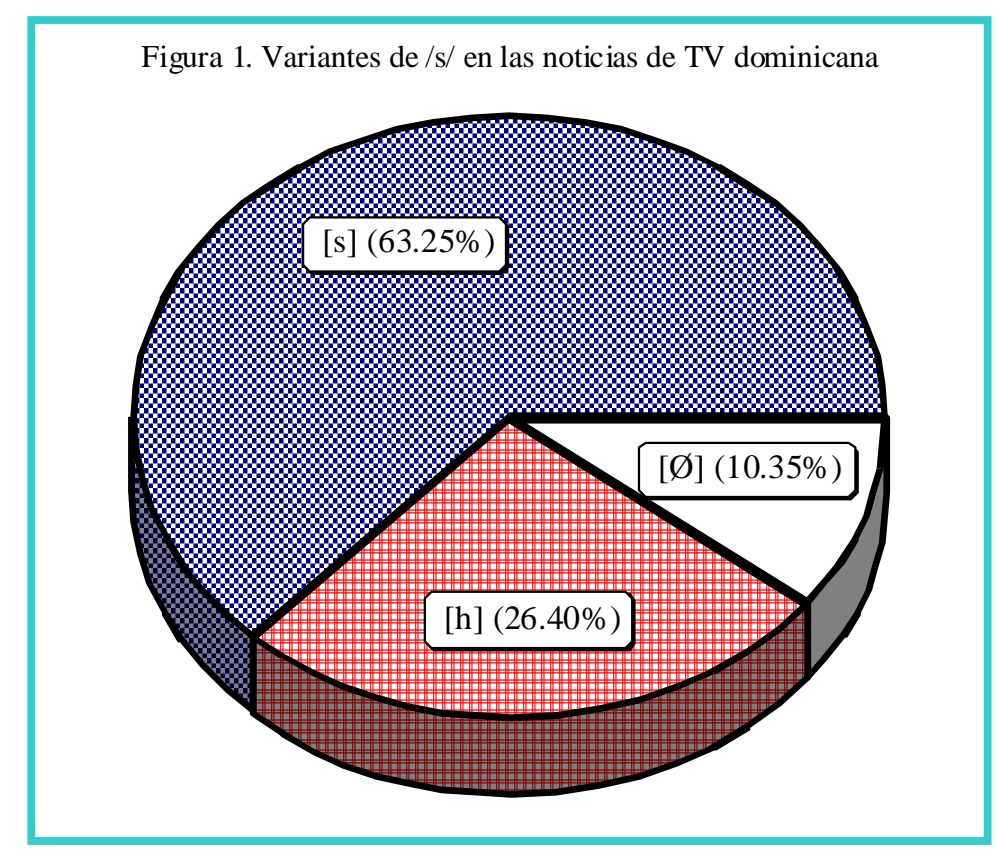

De entrada, es importante aclarar que los resultados anteriores incluyen la participación de una gran variedad de sujetos: presentadores, reporteros, obreros, políticos, campesinos, etc. Como en todas partes, el formato típico de los telediarios consiste en que el presentador inicia la noticia desde los estudios de televisión y a continuación da paso al reportero, quien, desde la calle o desde cualquier lugar donde se origine el hecho noticioso, explica, narra los acontecimientos y generalmente entrevista a los protagonistas o a los afectados por el evento. Esa variedad de participantes es la razón por la que la /s/ no aparece con una frecuencia mayor. Como es lógico suponer, el habla del hombre de la calle, sobre todo si este pertenece al sector bajo de la población, se caracteriza por incluir una mayor cantidad de elisiones o de reducciones fonéticas que la del periodista encargado de ofrecer las noticias por la televisión. 
Para ilustración del lector, se incluyen aquí dos muestras de los textos utilizados, en los que se destaca el sonido analizado. En la primera intervienen la presentadora, el reportero y el protagonista de la noticia. En la segunda solamente participan el presentador y un reportero.

\section{Muestra 1: Presentadora:}

«El presidente del Consejo Nacional de la Empresa Privada, CM, alertó hoy a las autoridades sobre los graves efectos y las nocivas repercusiones de algunos ajustes económicos contemplados por el Gobierno.»

\section{Reportero:}

«En momentos en que las autoridades gubernamentales no ocultan sus propósitos de aumentar las cargas impositivas, incrementar los precios de los combustibles y otros ajustes que han sembrado la preocupación y el desaliento en la población, el dirigente empresarial CM, alertó sobre los efectos y repercusiones de medidas de esa naturaleza.»

\section{Empresario:}

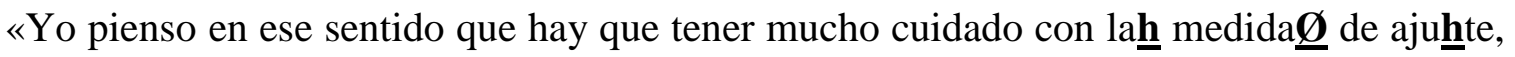
sobre todo porque nosotroh no tenemo $\underline{h}$ una crisis como la del año ochenta y nueve

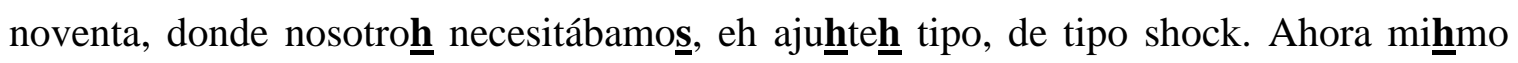
no, nosotroh tenemoh una macro economía ehtable, y cualquier medida necesaria para mantener esa estabilidad macro económica, pues debe de ser de forma tal que afecte menos a loh que menoh tienen.»

\section{Muestra 2: Presentador:}

«El Presidente, Leonel Fernández[s] $]$, ordenó mediante decreto la puesta en libertad de

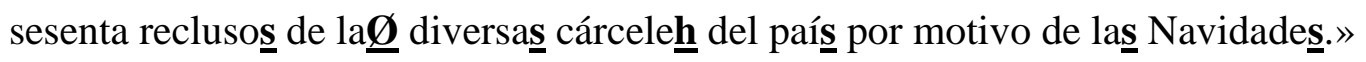

\section{Reportero:}

«Los indultos están contenido $\underline{\emptyset}$ en el decreto seiscientos cuarenta y cinco guion noventa y seis dado a conocer hoy por la oficina de prensa del Palacio Nacional, y el mismo es 
con efectividad a ește lunes. El mayor número de los indultados corresponden a la Penitenciaría de la Victoria, con doce, seguido por San Juan de la Maguana, con siete.»

Para situar los hechos anteriores en su contexto apropiado, resulta pertinente comparar los datos de las noticias con materiales del habla culta del país donde se emiten y al que van dirigidas las informaciones. Así se podrá tener una idea más precisa de las correspondencias, de las semejanzas o de las diferencias existentes entre las dos versiones.

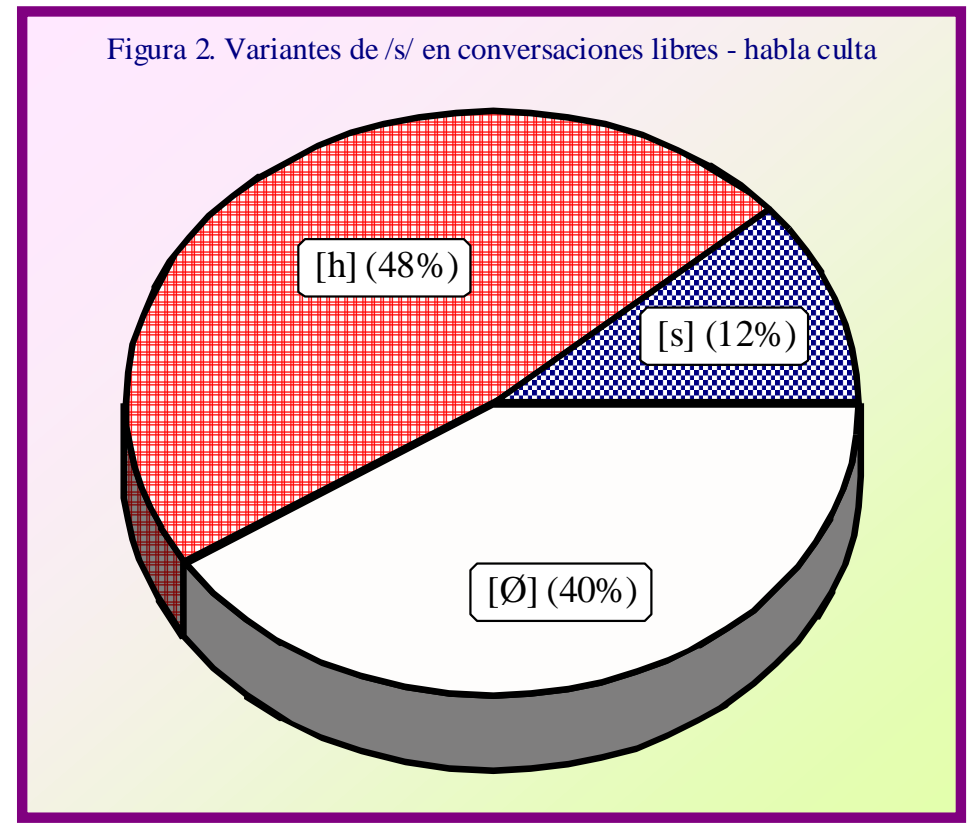

Con este fin, se incluye la figura 2, que recoge los datos de conversaciones libres de 35 hablantes profesionales, representativos del grupo sociocultural alto dominicano.

Es fácil observar que el rasgo que mejor caracteriza el estilo conversacional del grupo social alto es su preferencia por la aspiración de /s/ (48\%). Por su parte, la eliminación se sitúa en el $40 \%$, una cifra superior a la que arroja el habla de las personas del mismo grupo sociocultural en otras zonas hispánicas. ${ }^{2}$

\footnotetext{
${ }^{2}$ Por ejemplo, en San Juan de Puerto Rico (López Morales 1983) y en Las Palmas de Gran Canaria (Samper Padilla 1990), el proceso de desgaste fonético está menos avanzado que en territorio dominicano y la variante aspirada aparece con una frecuencia mucho más alta que la eliminación total. En el contexto final de palabra, los hablantes cultos de Las Palmas eliminan la /s/ en el 23.29\% de los casos y la aspiran en el 63.72\% (Samper Padilla 1990:121).
} 


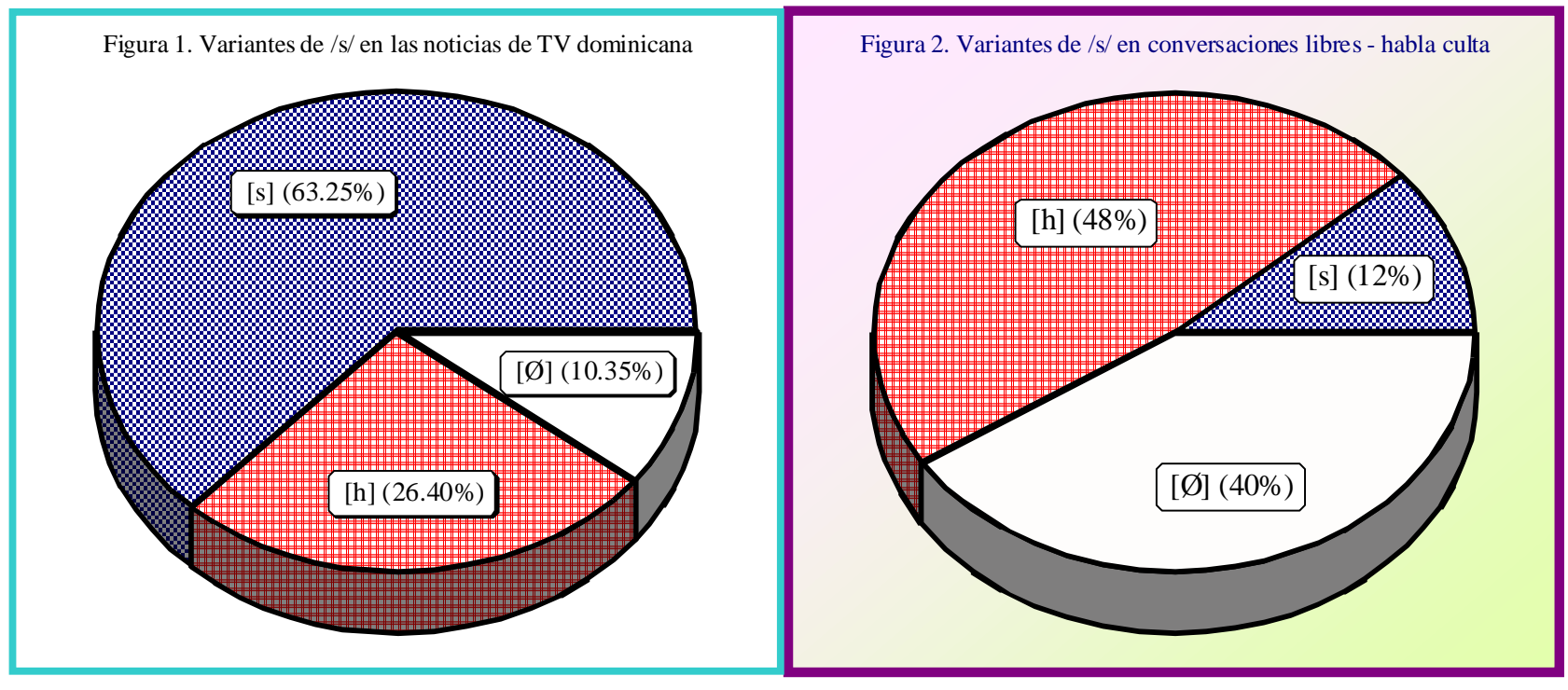

El cotejo de ambas figuras conduce a la conclusión de que la diferencia entre las dos modalidades lingüísticas (noticias y conversaciones) es muy grande. La presencia de la [s] es 5 veces mayor en las noticias de la televisión que en las conversaciones del grupo social alto; en cambio, la eliminación es 4 veces más frecuente en las conversaciones que en la televisión. La diferencia es menos dramática en el caso de la aspiración, en el que la variedad conversacional supera a la televisiva en una proporción de aproximadamente dos a uno.

Sin embargo, este contraste tal vez no resulta muy sorprendente si se toma en cuenta que se trata de dos versiones estilísticas muy diferentes. La situación y las circunstancias concretas en las que se ofrecen las noticias, ante las cámaras de televisión y con la intención de difundirlas públicamente, condicionan una actuación lingüística mucho más cuidadosa y formal que la que produce delante del encuestador un hablante en una conversación libre. Aunque este sepa que lo que dice está siendo grabado, dado que su acto de habla se realiza en un ambiente más o menos privado, no siente la misma presión que quien está frente a las cámaras de televisión. 


\section{PRESENTADORES Y REPORTEROS: UN CASO DE HIPERCORRECCIÓN}

Pero la meta de este artículo no es estudiar los datos globales de las noticias. Lo que interesa aquí es la pronunciación de los periodistas que las emiten, por lo cual se analizó por separado la producción de los presentadores y los reporteros. El conteo revela un índice de casi el 100\% de retención de /s/, lo que convierte su modalidad en una versión lingüística artificial en el ámbito dominicano. Su articulación casi invariable de la /s/ ilustra un caso extremo de hipercorrección, según el sentido acuñado para este término por Labov (1972:126), que lo utiliza para referirse al hecho de que los hablantes de clase media baja superan a los del estrato más alto en su tendencia a usar las formas consideradas correctas y apropiadas para estilos formales. ${ }^{3}$

La figura número 3 no puede ser más elocuente. La retención de la /s/ es sistemática en el habla de los presentadores y reporteros de las noticias. En un corpus de 1,260 casos de /s/ que fueron analizados, más de 99 de cada 100 fueron pronunciados de manera plena. Menos del uno por ciento fue objeto del proceso de relajamiento. ${ }^{4}$

Si los datos contenidos en esta figura se comparan con los de la número 2, que reúne los resultados de conversaciones libres de hablantes cultos, se comprueba que la oposición es tajante. De un $12 \%$ de retención que caracteriza el habla natural, conversacional, de los hablantes cultos dominicanos, se asciende a una tasa astronómica de más del $99 \%$ en el caso de los presentadores y reporteros de las noticias. Es, por tanto, extremadamente notable el contraste o la distancia entre su pronunciación y la del habla culta natural, incluso en los estilos más formales.

\footnotetext{
${ }^{3}$ No debe confundirse el término hipercorrección, como se define aquí, con el de ultracorrección, que en la tradición filológica hispánica se refiere al fenómeno que se produce cuando el hablante interpreta como incorrecta una forma correcta y la sustituye por la que entiende normal. En consecuencia, surge un tipo de reestructuración fonológica que genera una forma inaceptable, incorrecta (rus $\mathbf{t a}$, cuatros ). Como dice la Real Academia, se trata de la deformación de una palabra por equivocado prurito de corrección. La hipercorrección, en cambio, solo produce un aumento, un poco exagerado, de la frecuencia con que son usadas las formas de prestigio por un grupo con respecto a otro de más alto nivel sociocultural. El hecho consiste, por tanto, en un exceso cuantitativo de corrección.

${ }^{4}$ El estudio de Samper Padilla y Hernández Cabrera (2007:355-356) señala una situación muy diferente en las Islas Canarias, donde los presentadores de las noticias solo conservan la [s] en el $44.4 \%$ de las ocasiones, la aspiran en el $52.4 \%$ y la eliminan en el 3.2\%. Los corresponsales (reporteros) se muestran un poco más conservadores, y mantienen la [s] en el 59.9\% de los casos. Producen la aspiración [h] en el 36.3\% y la eliminación en el 3.7\%.
} 


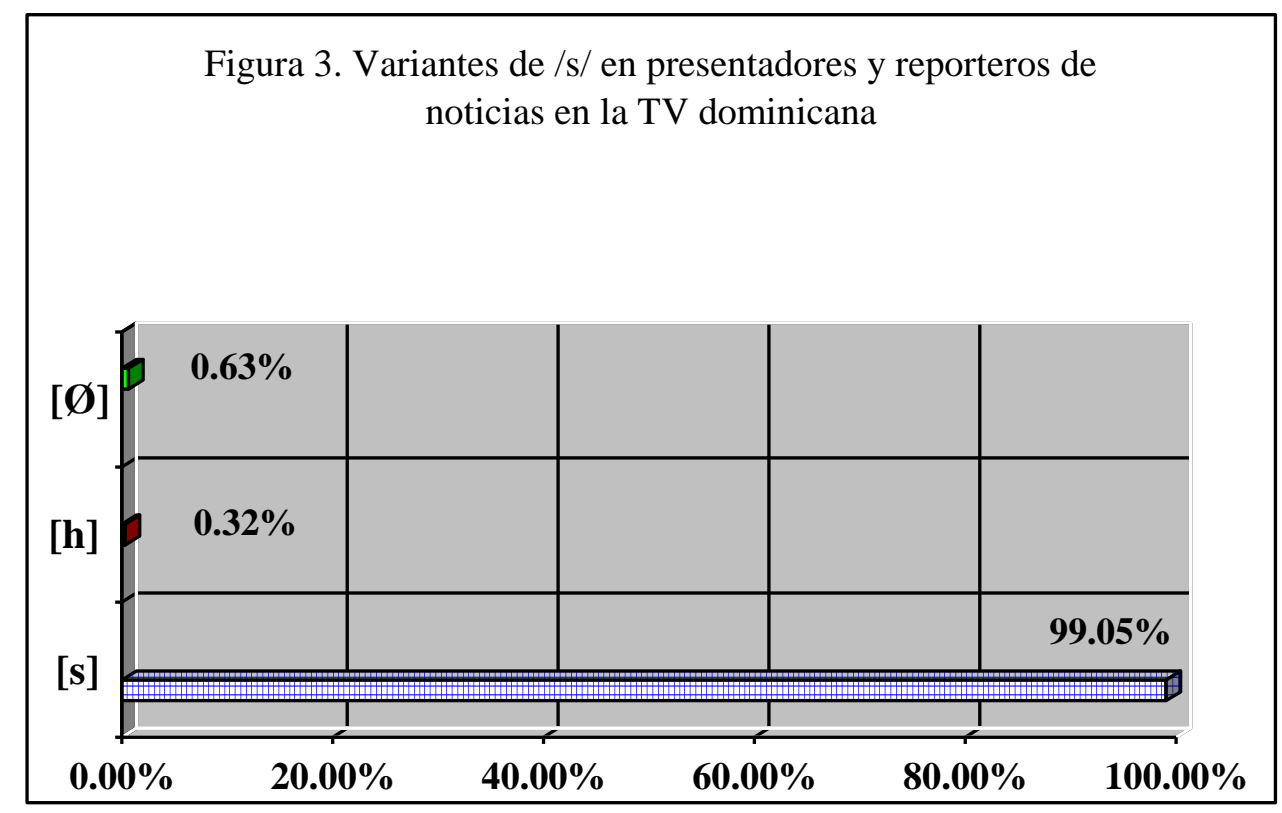

Para ilustrar de manera más clara los datos recogidos en la figura 3, se presentan a continuación varios ejemplos de textos producidos por locutores:

«Fuentes del Palacio Nacional revelaron este miércoles que podría sorprender a la ciudadanía la cantidad y los niveles de los funcionarios que serán sustituidos por el presidente Leonel Fernández[포] Señalaron que en las sustituciones se espera que también estén involucrados militares. Aseguran que en este caso ocurrirá algo sin precedentes en una gestión del presidente Leonel Fernández[s] $]$.»

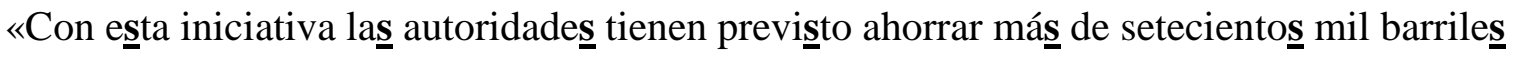
de petróleo equivalentes a cuarenta millones de dólares. Más de dos mil personas trabajan en el operativo de sustitución en barrios pobres del Distrito Nacional y la provincia Santo Domingo. Brigadistas tienen que cambiar un promedio de cincuenta y siete mil bombillos por día. Ește plan beneficiará a más de quinientas mil familias Las autoridades de Industria y Comercio suștituyen la cantidad de bombillos que tiene cada casa.» 
«Vamos a iniciar esta entrega con la autoridad metropolitana de transporte, que ha detenido cerca de dos mil vehículos en dos días, por circular sin renovar las placas. Los vehículos son retenidos en el llamado canódromo, donde los apurados dueños reconocen sus faltas y realizan gestiones tales como pagar la multa que encarece aún más el impuesto para renovar el marbete. Según voceros de la AMED, los vehículos son quitados a sus dueños cuando cometen alguna infracción, tras lo cual, al parecer, se dan cuenta de que no han renovado las placas y también de que tienen cristales rotos o les faltan las luces.»»

No es difícil comprobar que todas, absolutamente todas las /s/ presentes en los textos anteriores se conservan intactas. No se encuentra ni un solo caso de relajamiento o de reducción.

Frente al elevadísimo nivel de corrección de los textos anteriores, se descubre una situación muy diferente, de mayor adecuación a la realidad dialectal del país, en el siguiente fragmento, producido por un reconocido escritor, alto funcionario del área cultural del gobierno, como respuesta a la pregunta de una periodista de la televisión.

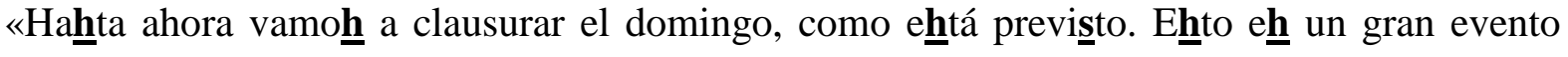
que, eh, incluye la participación de mucha gente. Loh editoreh internacionales se regresan ya

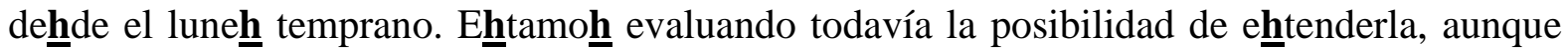
sea un día. Pero, oficialmente, aunque eso ocurra, la Feria debe clausurarse el domingo. Ya los representante $\underline{\emptyset}$ del paíh invitado de honor del año que viene han llegado al país. Y ehtarán también aquí el domingo. El ehpectáculo de clausura enhtá preparado...»

En este breve texto, el segmento /s/ colocado en posición final de sílaba o de palabra aparece en 21 ocasiones. Según se puede ver, del total de casos posibles, el hablante ha eliminado uno (al final de la palabra representantes) y ha conservado cuatro como sibilantes (en

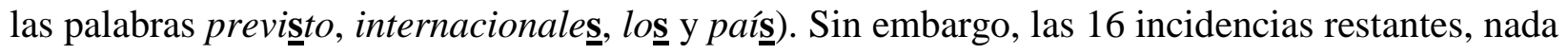
menos que el 76\%, se manifiestan en forma de una aspiración relajada [h].

Pero el antagonismo numérico descrito no es todo. Además del exceso de corrección en 
el aspecto cuantitativo por parte de los presentadores y los reporteros dominicanos, se comprueba también una exageración en la tensión articulatoria con que pronuncian la /s/. Esta peculiaridad es fácilmente perceptible por medio de una simple audición, sin necesidad de recurrir a refinados escrutinios. De cualquier manera, para verificar el hecho en forma inequívoca, se consideró conveniente realizar un análisis acústico de seis incidencias de la [s] final: tres pronunciadas por reporteros y presentadores, y tres de conversaciones de hablantes cultos. ${ }^{5}$ Aunque el examen experimental de estos datos no tiene pretensiones de exhaustividad ni de representatividad estadística, al menos permite señalar con claridad una tendencia generalizada: la mayoría de los presentadores y de los reporteros de las noticias televisivas en la República Dominicana practican una pronunciación que excede los límites de rigidez y de tensión propios del habla natural.

Por razones de espacio, solamente se incluyen aquí dos espectrogramas: uno por cada grupo de hablantes. La observación cuidadosa de las seis muestras revela que la duración de la /s/ final de palabra es mayor en los ejemplos extraídos de las noticias que en los pertenecientes al habla conversacional de personas cultas. El promedio de duración de los primeros es de 163 milésimas de segundo: 157 en la palabra veganas (dicha por un reportero); 202 en niveles (de un presentador) y 130 en sustituidos (un presentador). En cambio, la duración media de las eses pronunciadas en el habla culta conversacional es de 93 milésimas de segundo: 66 en la palabra medidas (un abogado); 108 en decisiones (un arzobispo) y 105 en médicos (un médico).

\footnotetext{
${ }^{5}$ Agradezco al colega Scott Alvord la sugerencia de reforzar la argumentación con este detalle y, de manera especial, a Erik Willis, de la Universidad de Indiana, su incalculable ayuda en el análisis acústico, que se llevó a cabo con el programa computacional Praat (Boersma, Paul \& Weenink, David (2008). Praat: doing phonetics by computer (versión 5.0.38) http://www.praat.org/
} 

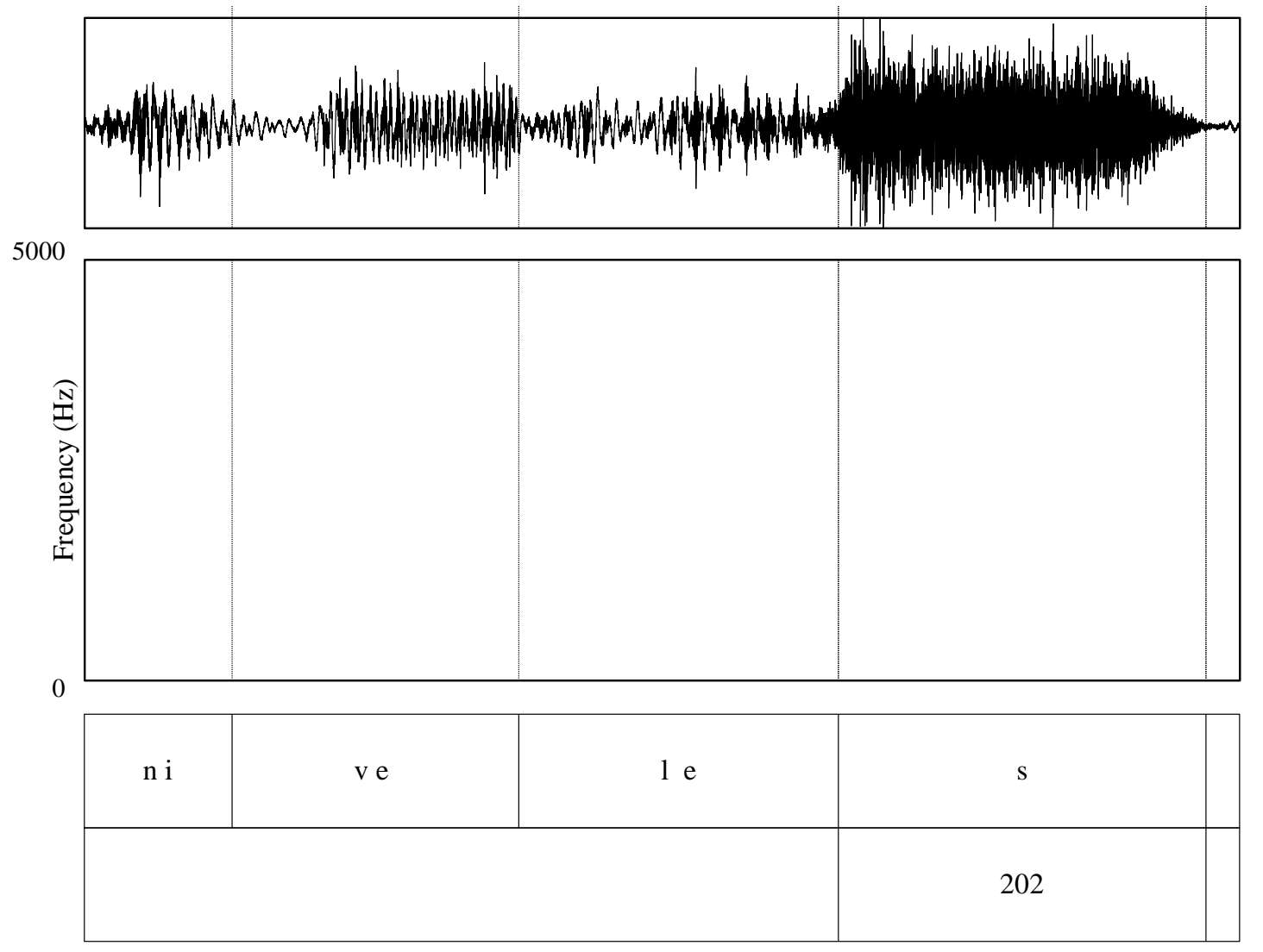

Time (s)

0.946

Figura 4. Espectrograma de la palabra "niveles - Presentador de noticias 

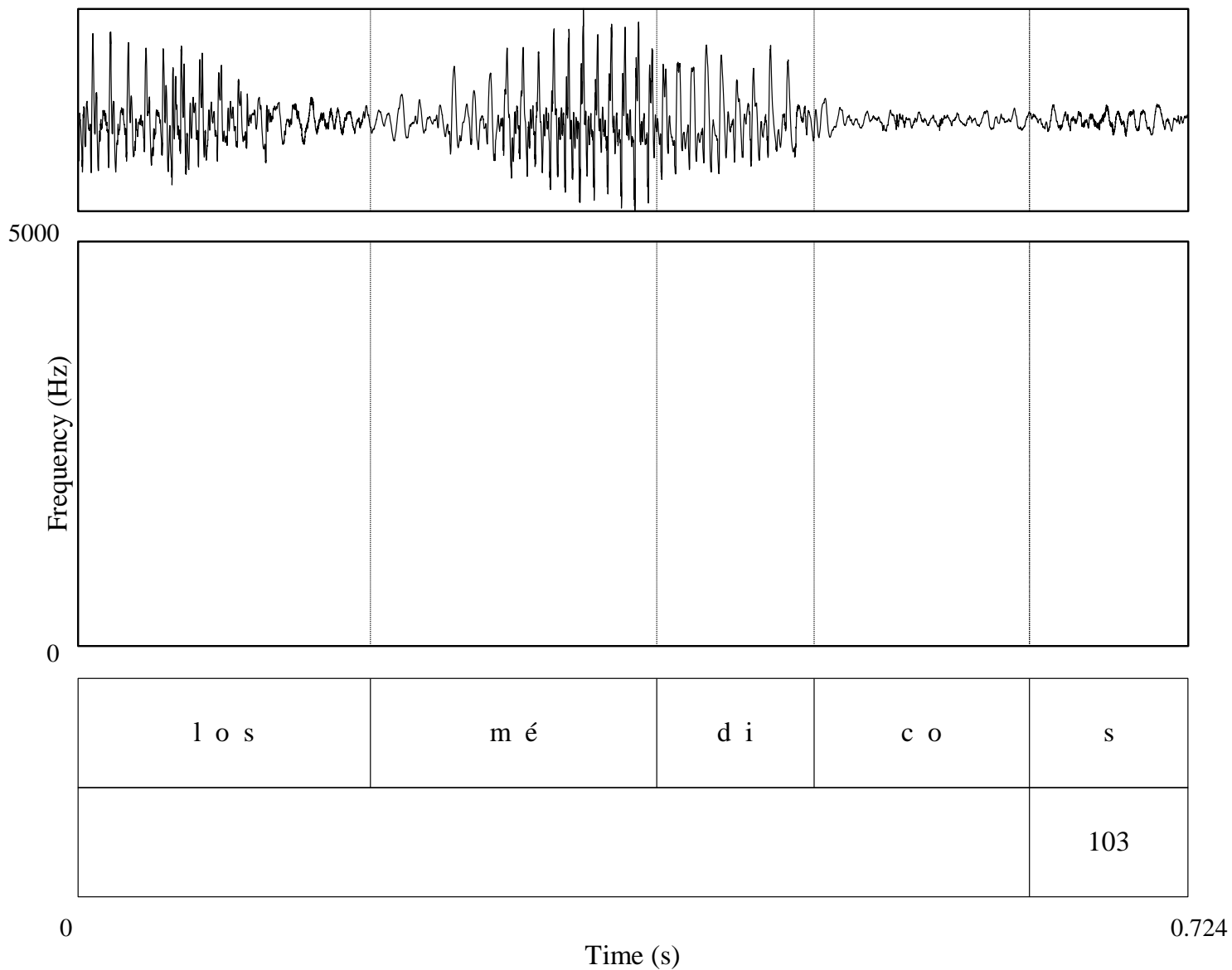

Figura 5. Espectrograma de “los médicoș” - Conversación de hablante culto

$\mathrm{Al}$ observar las figuras 4 y 5, se puede apreciar que el segmento [s] de la palabra niveles, pronunciada por un presentador (figura 4), cubre el doble del espacio que ocupa el de médico $\underline{\mathbf{s}}$ (figura 5), lo que quiere decir que aquel es un sonido con una duración notablemente superior a la de este. Como consecuencia de ello, no sería insensato suponer que la /s/ de la palabra niveles sea percibida como exagerada y artificial por los oyentes, independientemente de su nivel social. 
Otro detalle notable de la pronunciación de los informadores, especialmente cuando leen las noticias, es que tienden a hacer pausas en posiciones donde no corresponde y, en ocasiones, parece como si estuvieran intentando pronunciar palabra por palabra. Obsérvese el siguiente ejemplo, en el que las pausas aparecen indicadas con líneas verticales $\mid$ :

«Fuentes del Palacio Nacional revelaron | este miércoles $\mid$ que | podría | sorprender a

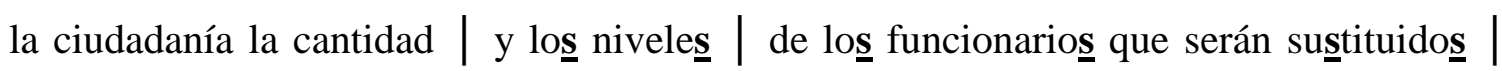
por el presidente Leonel Fernández[s] $]$ | Señalaron que en las $\mid$ sustituciones $\mid$ se espera que también estén involucrado $\underline{\mathbf{s}}, \mid$ militares. $\mid$ Aseguran que | en este caso ocurrirá | algo sin precedentes | en una gestión del presidente Leonel Fernández[s] $]$. |»

Como se puede apreciar, varias de las pausas se realizan en lugares inapropiados de la secuencia, creando una ruptura de la estructura sintáctica de la oración. Por ejemplo, se introduce un corte entre el subordinante que y el verbo dependiente podría, al que está íntimamente ligado. Asimismo, se ha hecho una pausa indebida entre niveles y de, y otra entre el artículo las y el sustantivo sustituciones, al que actualiza y con el que, naturalmente, debe formar una inseparable unidad sintáctica y de pronunciación. ${ }^{6}$

\section{CAUSAS DE LA HIPERCORRECCIÓN}

Hasta aquí se ha puesto en claro la existencia del fenómeno de la hipercorrección en las emisiones de los noticiarios dominicanos. Conviene ahora encontrar las razones que motivan este comportamiento. ¿Por qué los locutores, los presentadores y los reporteros de las noticias pronuncian con tanta frecuencia la /s/? ¿Qué los lleva a alejarse tanto de la norma culta de su país? En las próximas páginas se intentará plantear una serie de hipótesis o de posibles factores que aislada o conjuntamente podrían actuar como impulsores del fenómeno.

\footnotetext{
${ }^{6}$ Es también un rasgo llamativo de la pronunciación de muchos reporteros la adopción de unos patrones de entonación uniformes, repetitivos y monótonos, que se alejan de los propios del habla natural del país.
} 
Hipótesis \#1: la inseguridad lingüística

Un primer factor que podría servir como motor del fenómeno de la hipercorrección es el de la inseguridad lingüística que experimentan muchos dominicanos. Como se sabe, existe un estado de inseguridad lingüística cuando el hablante cree que su modo de hablar no es correcto y, en consecuencia, hay un desacuerdo entre las formas que él considera adecuadas y las que en efecto utiliza en su habla espontánea (Labov 1972, López Morales 2004).

Es un hecho confirmado que una parte importante de la población dominicana considera su modo de hablar como inferior y menos correcto que el de otros países. Y no solamente eso. También en otros aspectos de la cultura muchos dominicanos experimentan un sentimiento de inferioridad frente a los ciudadanos de otras naciones. Son oportunos, en este sentido, los comentarios expresados por el escritor dominicano León David en un artículo publicado en la versión digital del periódico $H O Y$, en junio de 2007. Aquí se citan fragmentos de ese trabajo.

«Muy a mi pesar me he visto obligado a admitir - no en una sino en múltiples ocasionesque nuestro pueblo no se estima a sí mismo y, por consiguiente, vaga por las calles arrastrando por el lodo el amor propio como si de un trapo se tratara.» «Y, por descontado, el menosprecio a lo nuestro va de manos con la desembozada tendencia a ensalzar todo lo de fuera. Lo autóctono es por antonomasia malo, feo y denigrable; lo foráneo -siempre que no proceda de Haití-, ostentará el brillo y las cualidades que por tan mezquina guisa en lo propio nos hemos empeñado en negar.» «Pues bien, para ahorrar al lector fatigosos preámbulos, iré al grano: nuestra inclinación a disminuir lo nacional y a magnificar lo extranjero se va a manifestar, entre otras cosas, en los nombres que hemos dado a sitios públicos y calles de la ciudad. ¿Por qué la avenida del malecón, sin duda la más hermosa de la capital, tiene que llamarse George Washington? ¿Por qué colocar a amplias y transitadas vías los nombres de Winston Churchill, John F. Kennedy o Charles de Gaulle, voces por otra parte impronunciables para el dominicano común?»

«Nos creemos tan poca cosa que acudimos presurosos al mérito real o supuesto del extraño en la esperanza de que algo se nos transfiera de su grandeza. Henos aquí, mutatis 
mutandis, frente al mismo mecanismo psicológico que induce a los padres a encasquetar a sus hijos los nombres de Peter, en lugar de Pedro, Tommy, en lugar de Tomás, o Daisy, en lugar de Margarita, sin darse por enterados que lo que ellos suponen enaltece, en verdad ridiculiza.»

La opinión expresada en los párrafos anteriores es extensible al terreno lingüístico. A este respecto, el conocido humorista dominicano Felipe Polanco (Boruga) caricaturiza el español del país de la siguiente manera en una de sus jocosas anécdotas:

«Y la forma de hablal. En ve de deci nosotro, decimo nojotro. Ello hay. Dede que uté oye una gente diciendo ello hay, e de aquí. Ello haberá que eperal. Poque eso e, tú sabe cómo e. Haiga, que ello haiga. Poque e que somo así. Entonce uno no se explica cómo gente que a vece viven en loma en otro paíse, hablan correctamente. Pero nosotro somo así y hay que quererno así.»

Dos ideas del párrafo anterior resultan particularmente reveladoras. La primera evidencia una sátira a la forma de hablar de los dominicanos («Dede que uté oye una gente diciendo ello hay, e de aquí.»). La segunda, en cambio, es una apología del español de otras partes («Entonce uno no se explica cómo gente que a vece viven en loma en otro paíse, hablan correctamente.»).

Con la intención de verificar con datos estadísticos la impresión de que muchos ciudadanos dominicanos tienen una idea negativa de su modo de hablar, hace varios años se realizó una encuesta en la que participaron 247 jóvenes universitarios de Santo Domingo y de Santiago. El estudio se llevó a cabo por medio de una escala tipo Likert, en la que se presentaba una serie de afirmaciones positivas y negativas ante las cuales los sujetos debían expresar su aceptación o su rechazo. Como se aprecia en la figura 6, la mayoría de los encuestados manifestó estar de acuerdo con la aseveración de que la variedad de español hablado por los dominicanos es inferior a la de países como España o Colombia. Esto ratifica la idea de que, efectivamente, existe en el país la tendencia a menospreciar lo autóctono, lo propio, y a enaltecer lo extranjero, lo ajeno. 
Figura 6. "El español hablado por los dominicanos es peor que el de otros países, como España o Colombia."

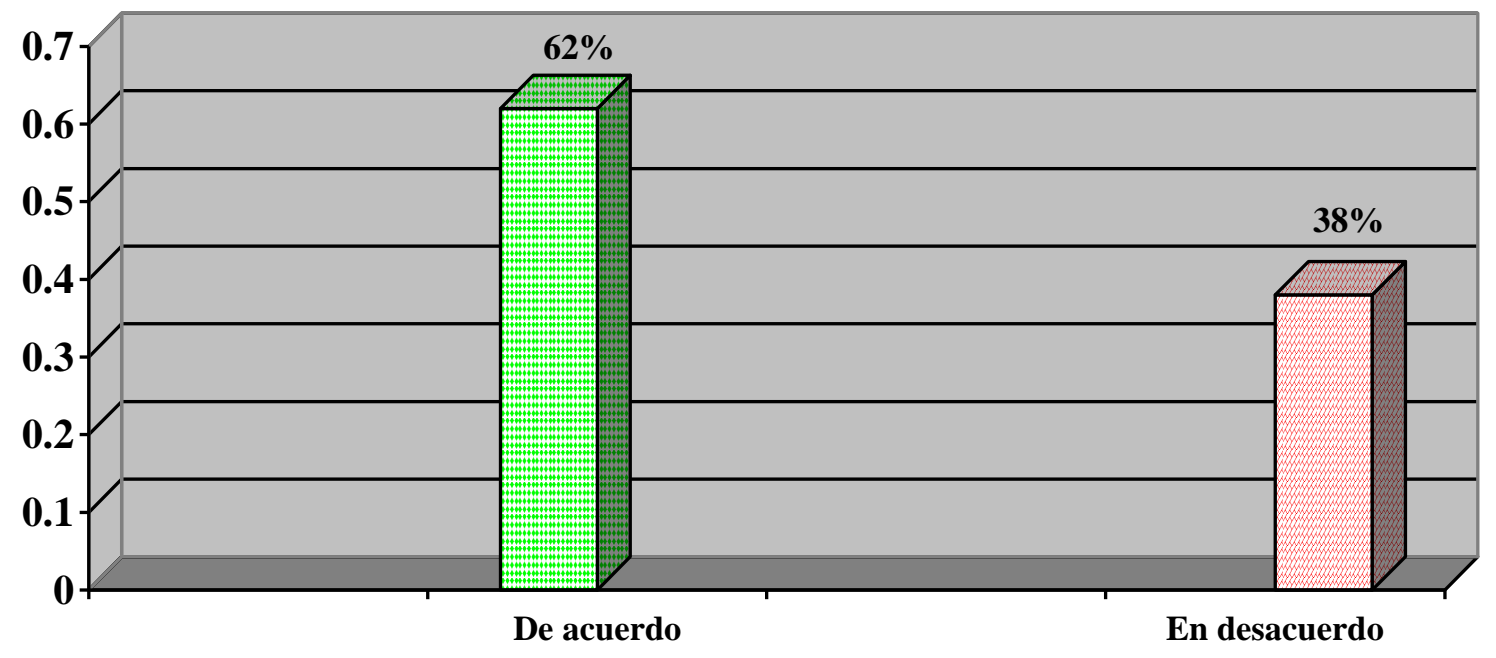

La idea central planteada en la hipótesis número uno es la siguiente: el sentimiento de inseguridad lingüística, que conduce a una especie de menosprecio del modo de hablar propio, puede motivar una reacción extrema, exagerada, de hipercorrección, de parte de los locutores, de los reporteros, de los presentadores y, por qué no, incluso de los productores de las noticias y los dueños de los medios orales de comunicación. Si esos comunicadores y empresarios creen que la lengua de los dominicanos no es correcta ni apropiada para usos formales, resulta lógico que, consciente o inconscientemente, intenten distanciar la manera de hablar empleada en la transmisión de las noticias del modo habitual como se expresan ellos mismos y los demás miembros de la comunidad en situaciones cotidianas. Y lo hacen, principalmente, utilizando el recurso de la retención sistemática del fonema /s/, cuya frecuente desaparición se ha convertido ya en emblema del habla popular ('incorrecta') dominicana.

El problema consiste en que al actuar de esa manera, en su intento por elevar su comportamiento lingüístico, sobrepasan el nivel de corrección que establece el habla culta formal de su país. Por eso resulta apropiado designar el fenómeno con el término hipercorrección. Y, lógicamente, el producto final consiste en una actuación fonética afectada, chocante, artificial, apartada de la norma o del modelo ideal de bien hablar que define la identidad lingüística de los dominicanos. 


\section{Hipótesis \#2: el mercado lingüístico}

Por otra parte, una de las hipótesis que podría dar respuesta parcial al problema es la del llamado mercado lingüístico, que postula que los hablantes que desempeñan ciertas ocupaciones tienden a usar una forma de lengua más correcta que otras personas de idénticas o muy parecidas características socioeconómicas. ${ }^{7}$ En este sentido, resulta muy comprensible que locutores, recepcionistas, actores y maestros, por ejemplo, dispensen mayor cuidado a su actuación lingüística que administradores, economistas, ingenieros, médicos, cuyas ocupaciones no requieren necesariamente una habilidad comunicativa especial. El empleo correcto y esmerado de la lengua determina en gran medida el éxito de la función de los primeros, pero no la eficacia del trabajo de los segundos. Ahí podría estar en parte la explicación del mantenimiento sistemático del segmento /s/ que exhiben los reporteros y presentadores de las noticias, en contraste con la articulación más relajada que caracteriza a los protagonistas de los hechos.

En varias ocasiones aparecen ejemplos que corroboran las ideas anteriores. Como muestra, se presenta uno de esos ejemplos.

\section{Reportera:}

«En eșta decimoprimera versión de la feria internacional del libro, los asistentes podrán disfrutar de una gran variedad de textos y material educativo que ofrecen las casas editoriales, y una diversidad de vistosos stand con informaciones diversas. CPT, consultor jurídico del Poder Ejecutivo, quien se considera amigo de los libros, realizó su primer recorrido por la feria.»

\section{Abogado:}

«Lo que he advertido hahta ahora me, me... entusiahma mucho y pienso terminarla, y sé que voy a tener que venir variah vece $\underline{\emptyset}$ para poder verla completa y poder dihfrutar a plenitud...»

\footnotetext{
${ }^{7}$ El concepto de mercado lingüístico fue esbozado por primera vez por Labov en 1966, en su conocido estudio sobre la estratificación social de /r/ en tres tiendas por departamentos de la ciudad de Nueva York. Sin embargo, son los investigadores canadienses D. Sankoff y S. Laberge (1978) quienes adoptan y elaboran esta noción con mayor precisión y detalle. 
En el primer texto, correspondiente a la reportera que desde la calle recoge la noticia, aparece un total de 16 casos de /s/ en posición final de sílaba o de palabra. Es muy revelador el hecho de que todas las posibilidades se conservan en forma plena, como [s]. En cambio, en el texto producido por el consultor jurídico del Poder Ejecutivo, un profesional que sociocultural y socioeconómicamente pertenece a un grupo superior al de la reportera, de 5 casos de /s/, ninguno se conserva en forma plena, uno se elimina y cuatro aparecen bajo la forma relajada [h].

\section{Hipótesis \#3: el estilo formal de lectura}

Se podría pensar que un factor determinante del alto nivel de conservación de la /s/ reside en el hecho de que la producción lingüística de los presentadores consiste generalmente en la lectura de unos textos dados y no en una elocución normal. Tal suposición parece tener mucho sentido. Según reconoce cualquier persona, y tal como saben muy bien los lingüistas que trabajan con una metodología de análisis sociolingüístico, la lectura en voz alta permite al hablante concentrar su atención en la pronunciación, ya que otros aspectos de la comunicación, como la selección léxica o el ordenamiento sintáctico de las palabras, vienen ya dados en el texto escrito.

Sin embargo, resulta significativo que los reporteros, aun cuando no leen, también exhiben el mismo nivel de corrección en lo que se refiere a la articulación de la /s/. El índice ya citado de retención de /s/ superior al $99 \%$ corresponde por igual al habla de presentadores y reporteros. El siguiente es un ejemplo producido por una reportera de noticias de un canal dominicano de televisión, en el que se puede observar que la /s/ se conserva en las 17 oportunidades existentes en el texto:

«Técnicos de la Cámara de Cuentas analizan cada detalle de los recursos de la Junta Central Electoral, destinados a la modernización de las Oficialías Civiles, ascendentes a treinta y cinco millones de dólares. La labor es como un balde de agua fría en el marco del conteo regresivo para las elecciones congresionales y municipales..»

Incluso, como se indicó antes con relación a las Islas Canarias (Samper Padilla y Hernández Cabrera 2007), se da el caso de que los reporteros (o corresponsales), que normalmente no leen, sino que detallan y amplían la noticia, superan en la retención de la /s/ a 
los presentadores, que generalmente leen la noticia. En los noticiarios de la televisión canaria, los primeros mantienen las eses en el $59.9 \%$ de las ocasiones, en tanto los segundos lo hacen solo en el $44.4 \%$.

Hipótesis \#4: el origen sociocultural bajo de algunos comunicadores

Un hecho muy estudiado es el avanzado estado en que se encuentra el proceso de eliminación de la /s/ final de sílaba y de palabra en la República Dominicana, sobre todo en los niveles bajos de la población. La figura 7 muestra que en el habla popular, los niveles de pérdida son elevadísimos. De cada 10 incidencias de la /s/, 9 se suprimen por completo. Tales cifras permiten pensar que la eliminación tan repetida de la consonante es rechazada socialmente, ya que resulta natural que el fenómeno se asocie estrechamente con la condición social de los hablantes que lo producen.

Figura 7. Variantes de /s/ implosiva en el nivel social bajo

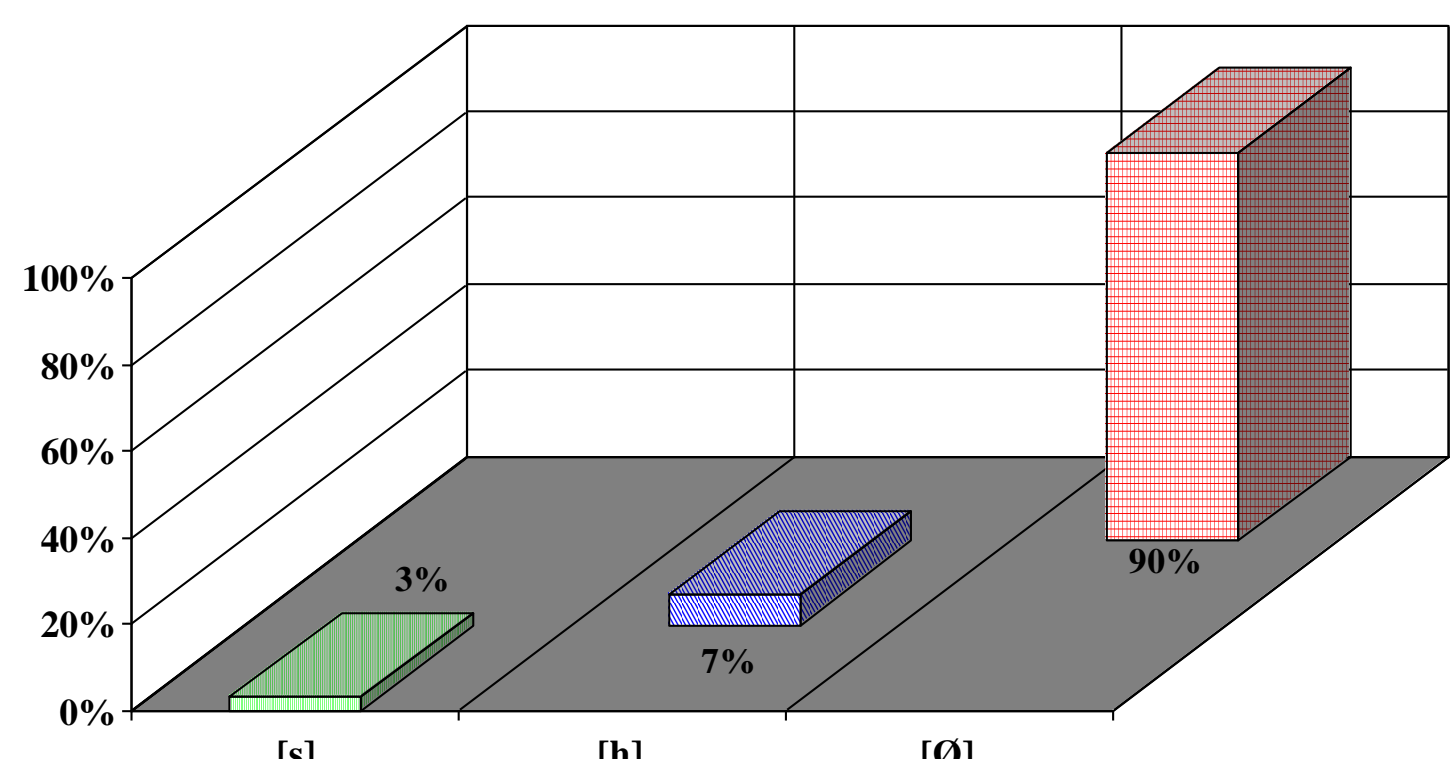

[s]

[h]

[Ø]

Aunque no existe una investigación que arroje conclusiones precisas al respecto, es un asunto de conocimiento público que algunos reporteros de la televisión dominicana proceden de los niveles sociales medio bajo o bajo de la población. En vista de que la tasa de eliminación de la /s/ es tan alta en estos sectores, sus miembros deben aprender artificialmente, en cierto sentido, 19 
el modo de hablar culto en la escuela o por otros medios, pero siempre fuera del ambiente familiar y de su propio grupo. En tales circunstancias, no sería extraño que dicho proceso diera como resultado un manejo de la pronunciación poco natural, aprendido, que no reflejara fielmente la variabilidad propia del habla culta auténtica. Esta se caracteriza principalmente, como se indicó antes, por unos porcentajes de la variante aspirada [h] que alcanzan el 48\%, por un nivel de eliminación que se sitúa alrededor del $40 \%$ y por el mantenimiento pleno de la /s/ en aproximadamente el $12 \%$ de las ocasiones. Podría especularse que quizá, en su empeño por hablar bien, los locutores procedentes de los sectores sociales bajos simplemente no logran adecuarse a estas proporciones. Saltan del límite, característico de su grupo de origen, en el que prácticamente se ha completado la etapa final de la reducción fonética, al extremo opuesto de la invariabilidad, conservando el $100 \%$ de los sonidos.

\section{Hipótesis \#5: la acción de la escuela de locución y de los directivos de las empresas noticiosas}

Existe en Santo Domingo una escuela de locución en la que se preparan muchos de los comunicadores que trabajan en los programas de noticias. En dicha escuela, se enseña y se exige a los alumnos que pronuncien «correctamente», que articulen de forma clara todos los sonidos. Como resultado de ello, muchos locutores exageran y podría decirse que tienden a hablar como un libro, exhibiendo una pronunciación claramente artificial. Por otra parte, hay que tomar en cuenta, como han atestiguado varios presentadores y reporteros, que los dueños de las empresas de comunicación y los productores de los programas les exigen un modo de pronunciación esmerado, correcto. Y para estos, la idea de lo correcto implica la pronunciación de todas las eses que contiene el texto.

Sin duda, se trata de un factor de mucho peso, porque desde la perspectiva de los locutores y de los reporteros, se puede argüir que es la política de la empresa donde trabajan la que los obliga a pronunciar de la forma como pronuncian. Brinda apoyo a esta interpretación la regularidad y la homogeneidad que se observa en su comportamiento lingüístico afectado y exagerado. De hecho, en ninguna de las muestras analizadas se encontró un solo caso que se apartara de la referida artificialidad. Sería lícito pensar, en consecuencia, que el factor determinante de su actuación lo constituye el hecho de no tener alternativa y no el posible estado de inseguridad lingüística, que bien podría jugar un papel reforzador de la conducta de unos, 
pero tal vez no de la de otros.

Sin embargo, en el caso de los dueños de emisoras, de los productores de programas y de los directivos de la escuela de locución, el razonamiento anterior es irrelevante y vacuo, porque son ellos quienes establecen las normas, sin estar subordinados a una autoridad superior. Así que, en definitiva, lo que parece explicar el surgimiento de la actuación hipercorrecta en los noticiarios de televisión es la inseguridad lingüística, porque si quienes ejercen una función directiva imponen como regla la pronunciación en forma tensa de cada una de las /s/ finales de sílaba presentes en un enunciado, lo hacen precisamente movidos por la creencia de que el modelo real y concreto del habla culta natural del país - que no conserva todas las eses- no es digno ni apropiado para el uso en las noticias de televisión.

\section{DISCUSIÓN}

Un recurso que puede ayudar a descubrir cuál de los cinco factores considerados es el que más contribuye a la presencia de la hipercorrección, consiste en averiguar si el fenómeno está o no está presente en otros países donde la /s/ también experimenta el proceso de reducción. Con ese fin se realizó un análisis de la pronunciación de la /s/ final de sílaba y de palabra en unos fragmentos de noticiarios de España (Sevilla y Tenerife), Argentina, Uruguay, Chile, Perú, Venezuela, Panamá, Cuba y Puerto Rico.

Resulta altamente significativo que en esas zonas del mundo hispánico la situación de hipercorrección no existe o no es tan marcada como en la República Dominicana. Un ligero examen de sus noticiarios revela una pronunciación más natural, en la que la variante aspirada [h] se repite con bastante frecuencia en el habla de los presentadores y los reporteros. En esos lugares, la distancia entre la pronunciación culta del país y la de la televisión no es tan grande como en la República Dominicana. Esto obliga a pensar, lógicamente, que tanto la hipótesis del mercado lingüístico como la del estilo de lectura, por ejemplo, no tienen suficiente validez, ya que esos factores están presentes en los noticiarios de todos los países. Por tanto, no parece arriesgado suponer que el comportamiento hipercorrecto que se descubre en la emisión de las noticias de la televisión dominicana, muy probablemente tiene su origen profundo en una reacción exagerada en busca de corrección, impulsada por la inseguridad lingüística que, como 21 
muchos de sus compatriotas, sufren los presentadores, los reporteros y los ejecutivos de los medios orales de comunicación del país.

Se ofrecen a continuación, como una simple muestra sin intención de representatividad, unos fragmentos muy breves tomados de las transmisiones por Internet de varios programas de noticias de los mencionados países del mundo hispánico. Fueron grabados cinco minutos de cada noticiario. Aquí se ofrecen unas líneas que dan una idea acertada de la pronunciación de la /s/ por parte de los presentadores y de los reporteros. Los casos de la articulación aspirada, relajada, se destacan subrayando y poniendo en negrita el símbolo $\underline{\mathbf{h}}$.

\section{Sevilla (España):}

«El desaparecido futbolihhta del Sevilla, Antonio Puerta, eh $\underline{\mathbf{h}}$ dehde hoy, hijo predilecto de la provincia, un nombramiento a título póhtumo que ha recogido su hermano Raúl. Otra hija predilecta de la provincia dehhde hoy, la gran Marifé de Triana, agradecía el título que le otorga su tierra, al tiempo que defendía la importancia de recibirlo en vida.»

\section{Tenerife (España):}

«Y esta noche en el cine Víctor se acoge el estreno del cortometraje Amanece. Participa en esta edición del festival de cortoh de Caja Canarias. Amanece retrata treh días en la vida de Teresa, que es una mujer trabajadora que ha rebasado la treintena, y de Claudio, su padre, con el que vive y con el que apenas se relaciona debido a un ohcuro hecho del pasado. Con

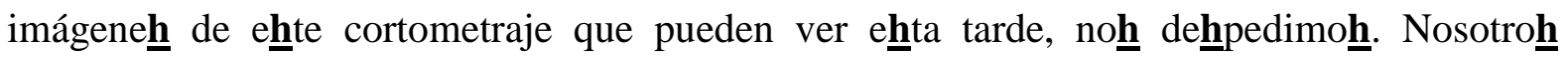
regresamon mañana a las tres. Pasen una feliz tarde. Adiós.»

\section{Argentina:}

«En la búhqueda siguen prófugo $\underline{h}$ loh delincuente $\underline{h}$ que mataron a un policía y a un comerciante durante el intento de asalto a una inmobiliaria de Lanús. El efectivo murió anteh de llegar al hoḥpital y el dueño del negocio dehpuéh de haber sido operado.»

\section{Chile:}

«Dehpuéh de cinco días de intensa lluvia y viento, así amaneció la cordillera. Prácticamente no nevó. La razón ehtá en la elevación del isoterma cero, el límite en el que el agua caída se congela y se transforma en nieve. Si éhte generalmente se ubica a loh doh mil setecientoh

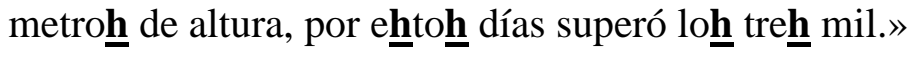




\section{Uruguay:}

«El ex ministro del Partido Nacional, del Ministerio de Economía y Finanzas, Ignacio de Posadas, indicó en una entrevihhta en el semanario Voceh $\underline{h}$ del Frente, justamente, que pondría lah manos, y que pone lah manos en el fuego por el ministro actual de Economía y Finanzah, Danilo Astori, por el caso Bengoa.»

\section{Perú:}

«La pobreza en el Perú disminuyó cinco punto doh por ciento en el dos mil siete. La cifra varió en cuarenta y cuatro punto cinco a treinta y nueve punto treh por ciento. El jefe del organismo, Renán Quispe, detalló que la mayor dihminución de la pobreza se registró en el área urbana.»

\section{Venezuela:}

«Un grupo de transportihhtah, protehtó hoy a las afuerah $\underline{h}$ de la sede del Ministerio del Poder Popular para la Infraehtructura. Rechazan la inseguridad que hay en el país, también la creación de la empresa denominada Sistema Integral de Transporte. Aseguran que de no obtener rehpuehta van a continuar llevando a cabo manifehtaciones.»

\section{Panamá:}

«Atensio manifehtó que entas son lah principales causas que inciden en el mal estado y poca durabilidad de lah carreteras. Aspecto en el que coincide con el hasta hace pocos días Director del Centro ehperimental de Ingeniería de la Universidad Tecnológica de Panamá, y ahora minihtro de Educación, Salvador Rodríguez.»

\section{Cuba:}

«Lázaro Barredo, director de Gramma, en la velada hizo entrega del original de 'Canción de cuna para dehpertar a un negrito', una poesía elhcrita por Nicoláh Guillén, en mil novecientos cincuenta y tres, y que se encontraba en los archivos del periódico Gramma.»

\section{Puerto Rico:}

«Chelsea Clinton reiteró en la ihla nena el compromiso de su madre de devolver y limpiar lah tierrah que fueron ocupadah por la Marina. Rafael Elín López noh tiene la noticia de primera plana.»

«En un acto estrictamente proselitihta, en el que otra vez, en el caso de la campaña Clinton, la prensa no puede preguntar, Chelsea Clinton caminó por lah calleh de Vieques y visitó 


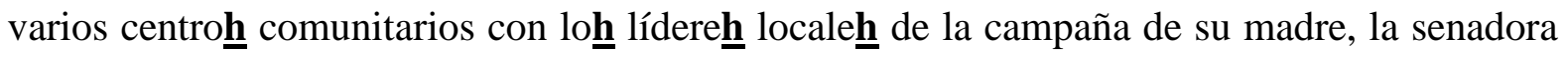
por Nueva York...»

Finalmente, a modo de recapitulación y para recalcar el punto central de esta exposición, se incluyen dos ejemplos más tomados de los noticiarios dominicanos en los que se confirma de nuevo la presencia invariable de la /s/ en su forma plena.

\section{República Dominicana:}

«Con esta iniciativa las autoridades tienen previs $\underline{s} t o$ ahorrar más de setecientos mil barriles de petróleo equivalentes a cuarenta millones de dólares. Más de dos mil personas trabajan en el operativo de sustitución en barrios pobres del Distrito Nacional y la provincia Santo Domingo.»

«Vamos a iniciar esta entrega con la autoridad metropolitana de transporte, que ha detenido cerca de dos mil vehículos en dos días, por circular sin renovar las placas vehículos son retenidos en el llamado canódromo, donde los apurados dueños reconocen sus faltas y realizan gestiones tales como pagar la multa que encarece aún más el impuesto para renovar el marbete.»

\section{CONCLUSIONES:}

Como era lógico esperar, el estudio comprueba la existencia de una diferencia importante entre la forma de pronunciación empleada en los informativos de la televisión y la que normalmente practican los miembros de la comunidad en situaciones comunes de la vida. Sin embargo, se verifica un contraste que más que visible y esperable, puede considerarse chocante. Por cada caso de [s] que los hablantes cultos retienen en conversaciones libres, las noticias mantienen cinco. De acuerdo con esto, es lícito afirmar que en la República Dominicana, las noticias de la televisión se transmiten haciendo uso de un modo de lengua súper conservador, hipercorrecto. 
El hecho adquiere dimensiones dramáticas en el caso específico de los presentadores y de los reporteros, cuya pronunciación ilustra un tipo especial de hipercorrección que roza la frontera de la invariabilidad. En sus intervenciones, alcanzan un índice de casi el $100 \%$ de retención de [s], convirtiendo en artificial su modalidad lingüística en el ámbito dominicano.

Según se ha expuesto, tal situación podría tener origen en cinco factores fundamentales: a. la inseguridad lingüística de los dominicanos; b. el mercado lingüístico; c. el estilo formal de lectura; d. el origen social bajo de algunos comunicadores; e. la acción de la escuela de locución y de los directivos de las empresas noticiosas.

El análisis presentado en este trabajo permite atribuirle mucha importancia al último de los factores expuestos. Si la política establecida por las empresas responsables de los programas de noticias obliga a los presentadores y los reporteros a practicar una determinada forma de pronunciación, a estos no les queda más remedio que acatar la disposición, independientemente de que estén o no de acuerdo con ella.

Ahora bien, la observación anterior no debilita la relevancia de la inseguridad lingüística como una de las causas principales y más probables del fenómeno. El hecho de que en muchos países hispánicos los presentadores y reporteros de las noticias de la televisión produzcan numerosos ejemplos de la variante relajada [h], reduce la probabilidad de que otros factores jueguen un papel causativo de la hipercorrección dominicana en la pronunciación de la /s/. Queda anulado, entre otros, el posible papel del estilo formal de lectura, porque de esa misma forma son ofrecidas las informaciones por los presentadores en los noticiarios de todas partes.

Los datos revelan que en tanto los presentadores y reporteros de otros países no tienen reparo en pronunciar variablemente la /s/, usando unas veces la variante [s] y otras la variante relajada [h], sus homólogos dominicanos y los directivos o patronos que los contratan, parecen avergonzarse del uso de la segunda, a pesar de ser la forma preferida por los hablantes cultos de su país. Tal vez no caen en la cuenta de que al hablar de esa manera despojan su actuación lingüística de dos de los rasgos más apreciados de todo comportamiento humano: la autenticidad y la naturalidad. Y lo que es peor aún: con su conducta hipercorrecta, contribuyen a acentuar el sentimiento de inseguridad lingüística de muchos de sus conciudadanos, que sienten distante y ajeno el español súper formal con el que se difunden las noticias. Así, sin proponérselo, incumplen una de sus funciones, porque como parte de su responsabilidad educativa, los medios 25 
de comunicación deben colaborar en la tarea de que los ciudadanos tomen conciencia y se sientan orgullosos de su identidad nacional. Para ello, sin tener que ser conformistas, deberían comenzar aceptando y asumiendo los valores que definen esa identidad. E indudablemente, entre esos valores, ocupa un lugar preferencial el modo de hablar la lengua, que funciona como la mejor tarjeta de presentación de los ciudadanos de cualquier nación.

\section{BIBLIOGRAFÍA}

ALBA, ORLANDO 1990. Variación fonética y estratificación social del español dominicano de Santiago. Santiago: Pontificia Universidad Católica Madre y Maestra.

2000. Nuevos aspectos del español en Santo Domingo. Santo Domingo: Librería La Trinitaria.

2004. Cómo hablamos los dominicanos. Santo Domingo: Grupo León Jimenes.

GONZÁLEZ, CARLISLE 1990. "El español dominicano: un estudio diatópico de /R/ y /L/", Anuario de Lingüística Hispánica, 6, pp. 225-253.

HACHÉ DE YUNÉN, ANA MARGARITA 1982. "La /n/ final de sílaba en el español de Santiago de los Caballeros", en El español del Caribe. Orlando Alba (ed.), Santiago: Universidad Católica Madre y Maestra, pp. 143-154.

JIMÉNEZ SABATER, MAXIMILIANO ARTURO 1975. Más datos sobre el español de la República Dominicana. Santo Domingo: Ed. INTEC.

LABOV, WILLIAM 1966. The social stratification of English in New York City. Washington. D.C.: Center for Applied Linguistics.

1984. Sociolinguistic patterns. Philadelphia: University of Pennsylvania Press.

LIPSKI, JOHN 1994. El español de América. Madrid: Cátedra. 
LÓPEZ MORALES, HUMBERTO 1983. Estratificación social del español de San Juan de Puerto Rico. México: Universidad Nacional Autónoma de México.

1990. "En torno a la /s/ final dominicana: cuestiones teóricas", Voz y Letra, 1, pp. 129137.

1992. El español del Caribe. Madrid: Editorial Mapfre.

2004. Sociolingüística. Madrid: Gredos.

MORENO DE ALBA, JOSÉ G. 2007. Introducción al español americano. Madrid: Arco Libros, S.L.

SAMPER PADILLA, JOSÉ ANTONIO 1990. Estudio sociolingüístico del español de Las Palmas de Gran Canaria. Las Palmas: Imprenta Pérez Galdós.

SAMPER PADILLA, JOSE ANTONIO y C. E. HERNÁNDEZ CABRERA. 2007. "La variación de -/s/ en los programas informativos de televisión en las Islas Canarias", en Estudios lingüísticos, literarios e históricos. Homenaje a Juan Martínez Marín. Granada: Editorial Universidad de Granada, pp. 349-361.

SANKOFF, DAVID y S. LABERGE. 1978. "The linguistic market and the statistical explanation of variability", en Linguistic variation. Models and methods, D. Sankoff (ed.), pp. $239-250$.

TERRELL, TRACY 1986. "La desaparición de /s/ pos-nuclear a nivel léxico en el habla dominicana", en Estudios sobre la fonología del español del Caribe, R. Núñez Cedeño, I. Páez Urdaneta y J. Guitart, eds., Caracas: La Casa de Bello, pp. 117-134.

VAQUERO, MARÍA 1998. "El español en los medios de comunicación de Puerto Rico (Radio, Televisión y Prensa): un estudio en marcha", La Torre. Revista de la Universidad de Puerto Rico, III, 7-8, pp. 501-510.

ZAMORA MUNNÉ, J. y J. GUITART. 1982. Dialectología Hispanoamericana. Salamanca: Ediciones Almar, S.A. 